\title{
Correction to: Bilateral atypical ulnar fractures occurring after long-term treatment with bisphosphonate for 7 years and with teriparatide for 2 years: a case report
}

Y. Asano $^{1} \cdot$ K. Tajiri $^{1} \cdot$ S. Yagishita ${ }^{1} \cdot$ H. Nakanishi ${ }^{1} \cdot$ T. Ishii $^{1}$

Published online: 20 October 2020

(C) International Osteoporosis Foundation and National Osteoporosis Foundation 2020

Correction to: Osteoporosis International https://doi.org/10.1007/s00198-020-05618-3

The original version of this article, published on 10 September 2020 contained a mistake.

Figure 2 was shown incorrectly. The correct version is given below:

The original article has been corrected.

The online version of the original article can be found at https://doi.org/ 10.1007/s00198-020-05618-3

Y. Asano

you.you.mounin@gmail.com

1 Department of Orthopaedic Surgery, Municipal Tsuruga Hospital, 1-6-60, Mishimamachi, Tsuruga-shi, Fukui 914-8502, Japan 

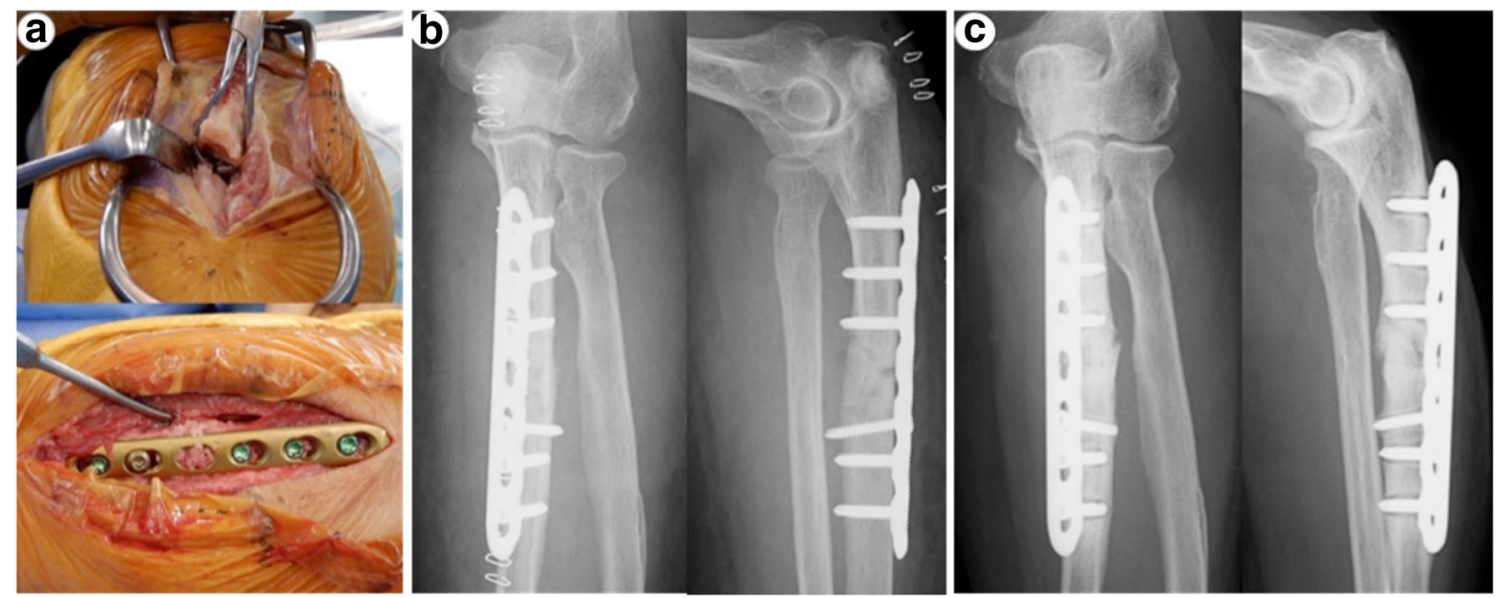

Fig. 2 a Intraoperative photographs showed cortical thickening and osteosclerotic changes at the fracture site, and an autologous cancellous bone graft from the ipsilateral olecranon was inserted. b Postoperative plain radiography. $\mathbf{c}$ Plain radiography of 1 year after surgery

Publisher's note Springer Nature remains neutral with regard to jurisdictional claims in published maps and institutional affiliations. 